\title{
Assay for the Quantitative Estimation of the Gonadotropin Inhibiting Material in Human Urine
}

\author{
NARgis P. BAGLI, K. G. RAJENDRAN, S. N. GHOSH AND P. N. SHAH \\ Endocrinology Unit, Cancer Research Institute, Parel, Bombay 12
}

\section{Synopsis}

\begin{abstract}
A method for the quantitative estimation of the gonadotropin inhibiting material (GIM) in human urine is standardised using the ovarian ascorbic acid depletion test, the results being expressed in terms of anti HCG units. A dose-response relationship with GIM is established. The reliability of the assay is demonstrated. Unlike other methods of assay this method is able to express precisely the quantity of GIM present in the urine. Preliminary data on GIM values in normal subjects as well as patients with endocrine disorders are presented.
\end{abstract}

The first report by Landau and his colleagues (1960) on the presence of a gonadotropin-inhibiting material (GIM) in human urine has been confirmed by various workers using different biological assay systems (Futterweit et al., 1963; Saito, 1965; Dronkert et al., 1965; Mahajan and Shah, 1966; Hipkin, 1967). Such gonadotropin inhibiting activity has also been demonstrated in other species like monkey (Sairam et al., 1966), cattle (Ayalon et al., 1970), and rat (Ota et al., 1970). The evidence available at present is insufficient to indicate the source of this material, though both the hypothalamus (Lastra and Arrau, 1967; Mahajan and Shah, 1970; Shah and Kothari, 1970) and the pineal (Soffer et al., 1965; Hipkin, 1970; Benson et al., 1972) have been suggested. Inspite of a number of reports on this subject the available assay systems (Landau et al., 1960; Futterweit et al., 1963; Mahajan and Shah 1966; Sairam et al., 1966; Hipkin 1967; Lastra and Arrau 1967; Ota et al., 1967; Benson et al., 1972) can only indicate whether the inhibitor

Received for publication October 8, 1973. is present or not and are ineffective as far as precise quantitation is concerned. Since this substance present in urine of man has been shown to be specifically anti-LH (Soffer and Fogel 1963), we attempted to take advantage of this property to assay it in terms of antiHCG units.

\section{Materials and Methods}

\section{Extraction of GIM}

The extraction of GIM was carried out by Butt's

Table 1. Design of experiments.

\begin{tabular}{lccc}
\hline & \multicolumn{2}{c}{ Injection I } & Injection II \\
\cline { 2 - 4 } Group & $\begin{array}{c}\text { HCG** } \\
\text { IU }\end{array}$ & $\begin{array}{c}\text { Hyalase* } \\
\text { 1U }\end{array}$ & $\begin{array}{c}\text { Test solution with } \\
12.5 \text { IU Hyalase }\end{array}$ \\
\hline 1. & - & 12.5 & - \\
2. & 2.0 & 12.5 & - \\
3. & 6.0 & 12.5 & - \\
4. & 6.0 & 12.5 & Dilution a \\
5. & 6.0 & 12.5 & Dilution 3 a \\
\hline
\end{tabular}

* Description of Hyalase.

Hyaluronidase B. P. (Ovine). Tata Fison Industries Ltd.

** Pregnyl Organon. 
method for gonadotropins (Butt, 1958), and the ether dried extract was dissolved in distilled water and heated in a boiling water bath for $90 \mathrm{~min}$ to destroy gonadotropin activity. The solution was then centrifuged and the supernatent was diluted to the required dose.

\section{Bioassay Procedure}

The assay was carried out by the modification of Modina and Polvani (1970) of the ascorbic acid depletion test for LH of Parlow (1961). Details of the assay scheme are given in Table 1 . Twenty six day old Holtzman strain rats were used, each group consisting of at least 4 animals. Ascorbic acid was determined in the ovarian extract and expressed as $\mu \mathrm{g}$ per $100 \mathrm{mg}$ ovary for each animal. The extent of neutralization by GIM of the ascorbic acid depletion due to HCG was calculated. Results were expressed in terms of antiHCG U/24 hr or anti-HCG U/1,000 ml urine in the case of pooled urine.

\section{Results}

The dose response curves for $\mathrm{HCG}$ and for HCG + GIM in one typical assay are shown in Figure 1. Parallelism of the curves was shown by the method of Gaddum (1953) $(\mathrm{p}>0.5)$.

Table 2. Reproducibility of the assay.

\begin{tabular}{llllllll}
\hline Assay No. & 1 & 2 & 3 & 4 & 5 & 6 \\
\hline
\end{tabular}

antilU HCG $/ 1,000 \mathrm{~m} l \quad 2.002 .662 .44 \quad 2.83 \quad 2.83 \quad 3.56$

Mean $=2.72$ anti $1 \mathrm{U} \mathrm{HCG} / 1,000 \mathrm{ml}$ urine

S.D. $=0.52$

C.V. $=18.96 \%$

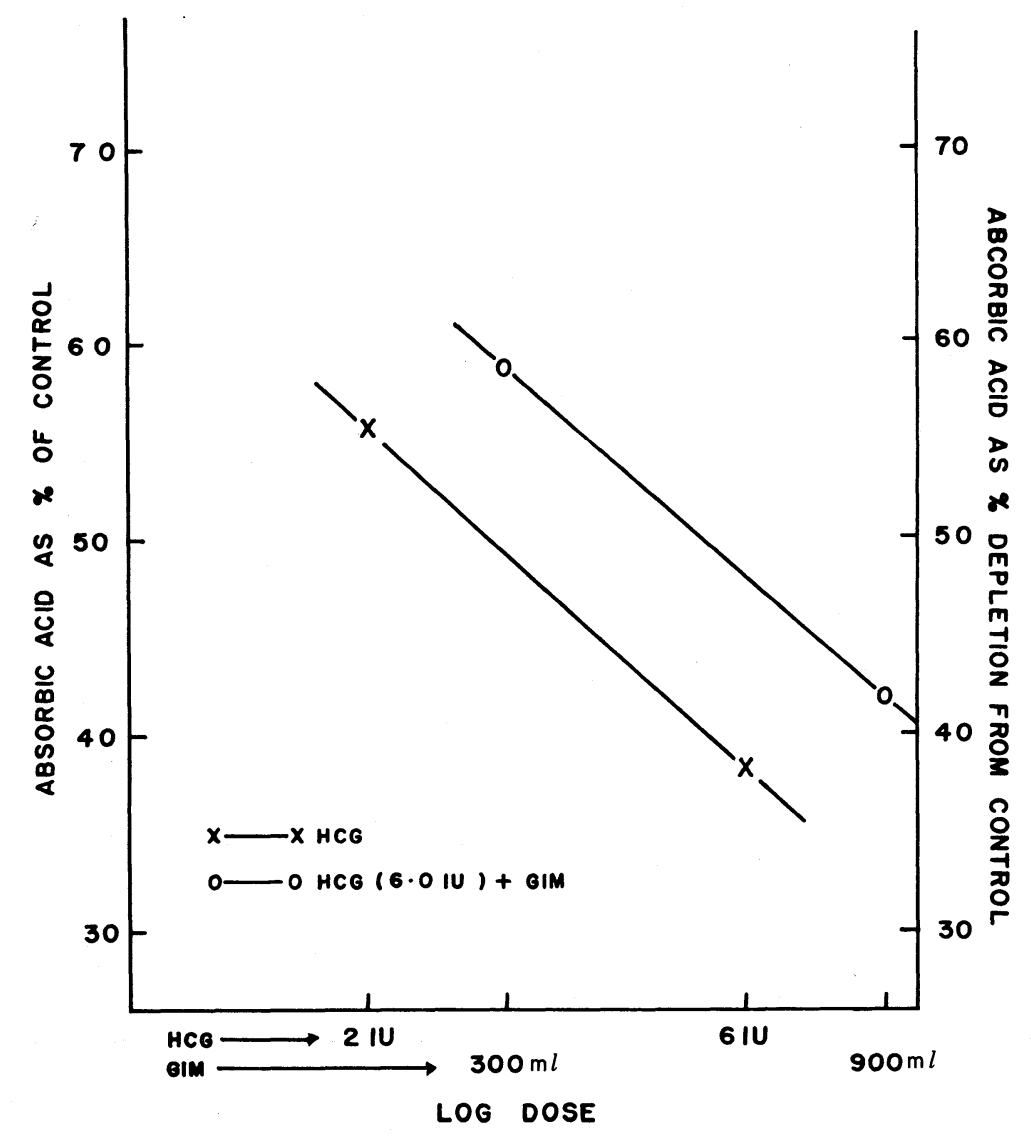

Fig. 1. Dose response curves with HCG and HCG + GIM activity at varying dosages. 
Table 3. Index of precision $(\lambda)$ in 26 assays

\begin{tabular}{cccccccc}
\hline$\lambda$ & $<0.10$ & $0.10-0.14$ & $0.15-0.19$ & $0.20-0.24$ & $0.25-0.29$ & $\geq 0.30$ \\
\hline No. of Assays & 0 & 7 & 8 & 4 & 3 & 4 \\
\hline
\end{tabular}

Mean $\lambda=0.22$

Table 4. Levels of GIM in a patient with Kallmann's syndrome

\begin{tabular}{lcc}
\hline Group & No. of animals & $\begin{array}{c}\text { Mean } \mu \mathrm{g} \text { ascorbic acid } \\
\text { per 100 mg ovary }\end{array}$ \\
\hline Control & 4 & 99.78 \\
2.0 IU HCG & 4 & 71.08 \\
6.0 IU HCG & 4 & 43.58 \\
6.0 IU HCG +12 hr-extract & 4 & 40.94 \\
\hline
\end{tabular}

Table 5. GIM levels in normals and patients with endocrine disorders.

\begin{tabular}{lccl}
\hline Sample & Sex & $\begin{array}{c}\text { GIM } \\
\text { anti-HCG U }\end{array}$ & Clinical status \\
\hline Pooled & M & $6.67 / 1,000 \mathrm{~m} l$ & Normal \\
Pooled & M & $3.95 / 1,000 \mathrm{~m} l$ & Normal \\
Pooled & M & $5.19 / 1,000 \mathrm{~m} l$ & Normal \\
Pooled & M & $2.71 / 1,000 \mathrm{~m} l$ & Normal \\
Pooled & F & $11.60 / 24 \mathrm{hr}$ & Normal \\
K.G.R & M & $9.83 / 24 \mathrm{hr}$ & Normal \\
P.N.S & M & $8.10 / 24 \mathrm{hr}$ & Normal \\
R.D & M & $7.50 / 24 \mathrm{hr}$ & Hypogonadotropic \\
& & $7.00 / 24 \mathrm{hr}$ & hypogonadism \\
& & $12.80 / 24 \mathrm{hr}$ & \\
N.D. & M & Absent & Kallmann's syndrome \\
M.V & F & $3.20 / 24 \mathrm{hr}$ & Forbes-Albright \\
& & & syndrome \\
\hline
\end{tabular}

Precision of the method was assessed by repeated estimations using an extract from a pooled sample of urine on different batches of animals (Table 2). The mean of 6 estimations was 2.72 anti-HCG U/1000 ml with a standard deviation of 0.52 . The coefficient of variation was $18.96 \%$. The mean index of precision of 26 bioassays was 0.22 (Table 3 ).

In order to demonstrate the specificity of the assay GIM was estimated in a patient with Kallmann's syndrome who was previously shown to have absence of GIM by the mouse uterine weight method (Shah and Kothari 1970). As can be seen from Table 4, there is no inhibition of HCG activity.

The results obtained in normal pooled and individual urine samples as well as in certain clinical conditions are shown in Table 5.

\section{Discussion}

As aforesaid, the presence of GIM in the urine of different species, including man, has been reported. However, serious limitations for quantitative estimations are encountered due to the unsuitability of the bioassay procedures employed. Percentage reduction of mouse uterine weight (Landau et al., 1960; Futterweit et al., 1963; Mahajan and Shah, 1966; Sairam et al., 1966; Hipkin, 1967), inhibition of PMS induced ovulation in rats (Lastra and Arrau, 1967) and mice (Ota et al., 1967) and the inhibition of compensatory ovarian hypertrophy in mice (Benson et al., 1972) are some of the bioassay end points. The methods thus detect only the presence of anti-gonadotropin activity in a given aliquot but cannot give a precise quantitation of this material per $24 \mathrm{hrs}$. Using Mondina and Polvani's modification of Parlow's ascorbic acid depletion assay, the present report establishes, as far as the authors are aware, for the first time a dose-response curve for GIM-activity and hence quantitation of this 
material in terms of anti-HCG units. The statistical parameters for the reliability criteria for the bioassay and the parallelism between the ascorbic acid depletion as percent of control in HCG treated rats and percent depletion from control of GIM treated rats show that the assay is valid (Fig. 1).

As it can be seen, the GIM values in male pooled urine ranges from 2.72-6.67 anti-HCG $\mathrm{U} / 1000 \mathrm{~m} l$ with a mean of 4.63 (Table 5). However, this range may not give a true picture of GIM excretion per $24 \mathrm{hr}$ since the volume of urine excreted per day varies due to climatic variations throughout the year.

Three separate estimations in a subject with hypogonadotropic hypogonadism gave a mean of 9.1 anti-HCG U/24 hr. This finding does not seem to differ from the values obtained in 2 normal subjects. The total absence of GIM in a subject with Kallmann's syndrome confirms the previous findings from this laboratory (Shah and Kothari 1970; Mahajan and Shah 1970), that patients with disorders of hypothalamic origin have low to absent levels of GIM. The implication of this observation vis-a-vis source of GIM can not be overlooked. It must be stressed that this presentation only emphasizes the development of a method for quantitation of GIM. It is hoped that with the availability of this method, large data would be collected to see variations, if any, in the excretory pattern in normal subjects as well as in pathophysiological conditions.

\section{References}

Ayalon, N., B. Landau and I. Lewis (1970). Int. J. Fertil. 15, 40.

Benson, B., M. J. Matthews and R. J. Orto (1972). Life Sciences 11, 669.
Butt, W. R. (1958). J. Endocr. 17, 143.

Dronkert, A., M. Ota and A. Gates (1965). Sixth Pan American Congress of Endocrinology, Mexico, Excepta Medica Int. Congr. Series 99, Abstract 168.

Futterweit, W., S. Margolis, L. J. Soffer and R. J. Dorfman (1963). Endocrinology 72, 903.

Gaduum, J. H. (1953). Pharmacol. Rev. 5, 87. Hipkin, L. J. (1967). J. Endocr. 38, 39.

Hipkin, L. J. (1970). Nature 228, 1202.

Landau, B., H. S. Schwartz and L. J. Soffer (1960). Metobolism 9, 85.

de la Lastra, M. and J. Arrau (1967). Eighth International Conference of IPPF., Santiago, Chile, P 453.

Mahajan, D. K. and P. N. Shah (1966). J. Reprod. Fert. 14, 532.

Mahajan, D. K. and P. N. Shah (1970). Ind. J. Med. Res. 58, 308.

Mondina, R. and F. Polvani (1970). Acta Endocr. 63, 609.

Ota, M., A. Dronkert and K. Obara (1967). Proc. 3rd Asia and Oceania Congress of Endocrinology, P 681.

Ota, M., K. S. Hsieh and K. Obara (1970). Endocr. Japon. 17, 333.

Parlow, A. F. (1961). Human Pituitary Gonadotropins (Edited by A. Albert), Charles C. Thomas, Springfield, P 300.

Sairam, M. R., H. G. Madhwaraj and N. R. Moudgal (1966). Endocrinology 78, 923. Saito, A. (1965). Can. J. Biochem. 43, 1711. Shah, P. N. and L. S. Kothari (1970). Endocr. Japon. 17, 221.

Soffer, L. J. and M. Fogel (1963). J. Clin. Endocr. 23, 870.

Soffer, L. J., M. Fogel and A. Z. Rudavsky (1965). Acta Endocr. 48, 561. 